\title{
Physical activity correlates among people with psychosis: Data from 47 low- and middle-income countries 2 ?
}

\author{
Brendon Stubbs ${ }^{\text {a,b,*,1 }}$, Davy Vancampfort ${ }^{\mathrm{c}, \mathrm{d}, 1}$, Joseph Firth ${ }^{\mathrm{e}, \mathrm{r}}$, Mats Hallgren ${ }^{\mathrm{f}}$, Felipe Schuch ${ }^{\mathrm{g}, \mathrm{h}}$, \\ Nicola Veronese ${ }^{\mathrm{i}}$, Marco Solmi ${ }^{\mathrm{i}, \mathrm{j}}$, Fiona Gaughran ${ }^{\mathrm{a}, \mathrm{b}}$, Kai G. Kahl ${ }^{\mathrm{k}}$, Simon Rosenbaum ${ }^{\text {l }}$, Philip B. Ward ${ }^{\mathrm{m}, \mathrm{n}}$, \\ Andre F. Carvalho ${ }^{\circ}$, Ai Koyanagi ${ }^{\mathrm{p}, \mathrm{q}}$
}

a South London and Maudsley NHS Foundation Trust, Denmark Hill, London SE5 8AZ, United Kingdom

b Institute of Psychiatry, Psychology and Neuroscience, King's College London, De Crespigny Park, London, Box SE5 8AF, United Kingdom

c $K U$ Leuven Department of Rehabilitation Sciences, Leuven, Belgium

${ }^{\mathrm{d}}$ KU Leuven, University Psychiatric Center KU Leuven, Leuven, Kortenberg, Belgium

e Division of Psychology and Mental Health, University of Manchester, Manchester, United Kingdom

${ }^{\mathrm{f}}$ Department of Public Health Sciences, Karolinksa Institute, Stockholm, Sweden

${ }^{g}$ Unilasalle, Canoas, Brazil

${ }^{\text {h }}$ Hospital de Clínicas de Porto Alegre, Porto Alegre, Brazil

i Institute of Clinical Research and Education in Medicine (IREM), Padova, Italy

j National Research Council, Neuroscience Institute, Aging Branch, Padova, Italy

${ }^{\mathrm{k}}$ Department of Psychiatry, Social Psychiatry and Psychotherapy, Hannover Medical School, Hannover Medical School, Hannover, Germany

${ }^{1}$ School of Psychiatry, UNSW Australia, The Black Dog Institute, University of New South Wales, Prince of Wales Hospital, Sydney, Australia

m School of Psychiatry, UNSW, Sydney, Australia

" Schizophrenia Research Institute, Ingham Institute of Applied Medical Research, Liverpool, Australia

${ }^{\circ}$ Department of Clinical Medicine and Translational Psychiatry Research Group, Faculty of Medicine, Federal University of Ceará, Fortaleza, CE, Brazil

${ }^{\mathrm{p}}$ Research and Development Unit, Parc Sanitari Sant Joan de Déu, Universitat de Barcelona, Fundació Sant Joan de Déu, Dr. Antoni Pujadas, 42, Sant Boi de Llobregat, Barcelona 08830, Spain

ฯ Instituto de Salud Carlos III, Centro de Investigación Biomédica en Red de Salud Mental, CIBERSAM, Monforte de Lemos 3-5 Pabellón 11, Madrid 28029, Spain

${ }^{\mathrm{r}}$ NICM, School of Science and Health, University of Western Sydney, Australia

\section{A R T I C L E I N F O}

Article history:

Received 11 February 2017

Received in revised form 13 June 2017

Accepted 14 June 2017

Available online $\mathrm{xxxx}$

\section{Keywords:}

Physical activity

Exercise

Developing countries

Mobility

Psychiatry

Psychosis

Schizophrenia

\section{A B S T R A C T}

Background: People with schizophrenia engage in low levels of physical activity (PA). However, few large-scale studies have investigated the factors that may influence PA participation in individuals with psychosis and data from low- and middle-income countries (LMICs) is especially scarce. Thus, we investigated PA correlates in a large sample of people with a psychosis diagnosis across 47 LMICs.

Methods: Cross-sectional data from the World Health Survey, restricting to those with a self-reported lifetime diagnosis of schizophrenia/psychotic disorder, was analyzed. PA was assessed by the International Physical Activity Questionnaire (IPAQ) and participants were dichotomized into those that do and do not (low PA) meet the minimum recommended PA weekly targets ( $\geq 150 \mathrm{~min}$ ). A range of socio-demographic, health behavior, and mental and physical health variables were examined using random effects logistic regression.

Results: Overall 2407 people (mean 42.0 years, $41.5 \%$ males) with schizophrenia/psychosis were included. The prevalence of low PA was 39.2\% (95\%CI = 37.0\%-41.2\%). Male sex (odds ratio $(\mathrm{OR})=1.33$ ), increasing age, unemployment (vs. employed $\mathrm{OR}=2.50$ ), urban setting (vs. rural OR $=1.75$ ), inadequate fruit consumption (vs. adequate fruit intake $O R=3.03)$, depression $(O R=1.33)$, sleep/energy disturbance, and mobility limitations were significantly associated with low PA. Marital status, education, wealth, smoking, vegetable and alcohol consumption, anxiety, cognition, pain, and chronic medical conditions were not significant correlates.

Conclusion: PA is influenced by a range of factors among people with psychosis. These correlates should be considered in interventions aiming to facilitate PA in psychotic individuals living in LMICs.

(c) 2017 Elsevier B.V. All rights reserved. it Funding - This paper received no specific grant or direct funding.

* Corresponding author at: Physiotherapy Department, South London and Maudsley

NHS Foundation Trust, Denmark Hill, London, United Kingdom.

E-mail address: brendon.stubbs@kcl.ac.uk (B. Stubbs).

1 Joint first authors.

\section{Introduction}

In the general population, there is an abundance of evidence that physical activity (PA) is associated with good health, including reduced cognitive decline (Hamer and Chida, 2009) and decreased risk of 
cardiovascular disease and associated mortality (Naci and Ioannidis, 2013). Moreover, PA may protect against mental health conditions such as depression (Mammen and Faulkner, 2013), promotes healthy aging (Hamer et al., 2014), and is associated with better quality of life (Nelson et al., 2007). In light of this, international organizations (e.g. World Health Organization, 2014) have recommended that people should attempt to achieve 150 min of moderate to vigorous PA per week, which could include $30 \mathrm{~min}$ of aerobic PA (such as brisk walking, playing sports, using the gym) five times per week.

Perhaps unsurprisingly, a recent meta-analysis of 35 studies incorporating 3453 individuals with psychosis demonstrated that $43.4 \%$ fail to achieve 150 min of moderate-vigorous PA per week, a figure $50 \%$ higher than that of age- and sex-matched controls in the general population (Stubbs et al., 2016a). Clearly this is a concern, given the wider health benefits of PA in the general population. Moreover, there is consistent evidence that engaging in PA and exercise can improve a plethora of outcomes in patients with psychosis, such as cognition (Firth et al., 2016b), cardiorespiratory fitness (Vancampfort et al., 2016b), cardio-metabolic risk factors, and quality of life (Firth et al., 2015). Given this, understanding factors associated with PA in people with schizophrenia are essential to develop population-level interventions to increase PA (Firth et al., 2016a). A previous systematic review across 25 studies and 25,013 people with schizophrenia found that negative symptoms, low motivation, cardio-metabolic risk factors, and social isolation were associated with low PA (Vancampfort et al., 2012). However, this literature was confined to high-income countries and no studies were found in low- and middle-income countries (LMICs) despite the high prevalence and burden of mental disorders in LMICs (Weinmann and Koesters, 2016). While in the general population it is estimated that low PA is more evident in high-income countries (World Health Organization, 2014), there are increasing concerns about this in LMICs (Vancampfort et al., 2017). In addition, most PA correlate studies to date have included small sample sizes ( $<100$ people) from a single country, thus limiting generalizability.

Given these gaps and limitations within the literature, the current study aimed to investigate the correlates of PA among communitydwelling individuals with a self-reported lifetime diagnosis of schizophrenia/psychosis in a large sample across 47 LMICs.

\section{Methods}

\subsection{Settings and protocol}

The World Health Survey (WHS) was a cross-sectional study undertaken from 2002 to 2004 in 70 countries worldwide. The details of the survey including the questionnaires are available from the WHO website (http://www.who.int/healthinfo/survey/en/). Briefly, singlestage random sampling or stratified multi-stage random cluster sampling was conducted depending on the country. Those aged $\geq 18$ years with a valid home address were eligible to participate. Each member of the household had equal probability of being selected. Trained interviewers conducted face-to-face or telephone interviews. A standardized questionnaire was used in all countries with some countries using a shorter version. The individual response rate across all countries was 98.5\% (Nuevo et al., 2012). Ethical approval was obtained from ethical boards at each study site. Informed consent was obtained from all participants.

\subsection{Variables}

\subsubsection{Physical activity (PA)}

In order to assess if participants completed the recommended PA levels of 150 min of moderate to vigorous PA per week (Vancampfort, 2012), we used the International Physical Activity Questionnaire (Craig et al., 2003). The total amount of moderate to vigorous PA over the last week was calculated based on self-reported (time spent physically active and frequency) moderate and high intensity PA combined. Those scoring $\geq 150 \mathrm{~min}$ of moderate to high intensity PA were classified as meeting the recommended guidelines (coded 0 ), and those scoring $<150 \mathrm{~min}$ (low PA) were classified as not meeting the recommended guidelines (coded 1).

\subsubsection{Socio-demographics}

These included information on sex, age, marital status [married/cohabiting or other (never married/separated/divorced/widowed)], highest education attained (at least secondary completed or not), wealth quintiles, employment status (unemployed or not), and setting (rural or urban). Principal component analysis based on 15-20 assets was performed to establish country-wise wealth quintiles. Employment status was assessed with the question 'What is your current job?' Those who answered 'not working for pay' were considered to be unemployed.

\subsubsection{Health behaviors}

The question 'Do you currently smoke any tobacco products such as cigarettes, cigars, or pipes?' with the answer options, 'daily', 'yes, but not daily', or 'no, not at all' identified smokers. Those who replied 'daily' or 'yes, but not daily' were considered to be current smokers. Two separate questions for fruits and vegetables were used to assess the amount of servings the participant eats on a typical day. The answer to these questions were dichotomized as $<5$ or $\geq 5$ servings/day following WHO/FAO recommendations (Bishwajit et al., 2017). Alcohol consumption was assessed by first asking the question 'Have you ever consumed a drink that contains alcohol (such as beer, wine, etc.)?' Respondents who replied 'no' were considered lifetime abstainers. Those who replied affirmatively were asked how many standard drinks of any alcoholic beverage they had on each of the past 7 days. The number of days in the past week in which four (females) or five (males) drinks were consumed was calculated (World Health Organization, 2002); a total of 1-2 and $\geq 3$ days in the past 7 days were considered infrequent and frequent heavy drinking respectively. All other respondents, apart from lifetime abstainers, were considered non-heavy drinkers.

\subsubsection{Mental health}

Depression was defined using the DSM-IV algorithm, based on duration and persistence of depressive symptoms in the past 12 months (Cifuentes et al., 2008; Loerbroks et al., 2012). Anxiety was assessed by the question 'Overall in the past 30 days, how much of a problem did you have with worry or anxiety' with answer options being none, mild, moderate, severe, and extreme. Those who answered severe and extreme were considered to have anxiety (Koyanagi and Stickley, 2015; Wong et al., 2013). We used the extreme categories for their potential clinical relevance. Details for the variables on sleep/energy and cognition are provided in Section 2.2.6.

\subsubsection{Physical health}

Arthritis, asthma, and diabetes were based solely on self-reported lifetime diagnosis. For angina, in addition to a self-reported diagnosis, a symptom-based diagnosis based on the Rose questionnaire was also used (Rose, 1962). Chronic back pain was defined as back pain (including disc problems) every day during the last 30 days. Visual impairment was defined as extreme difficulty in seeing and recognizing a person that the participant knows across the road (i.e., from a distance about $20 \mathrm{~m}$ ) (Freeman et al., 2013). The total number of these conditions was calculated. Details on the pain/discomfort and mobility difficulty variables are provided in the section below (Section 2.2.6).

\subsubsection{Health status (sleep/energy, cognition, pain/discomfort, mobility)}

Participants' health status was evaluated with eight health-related questions pertaining to four domains: (a) sleep/energy; (b) cognition; (c) pain/discomfort; (d) mobility. Each domain consists of two questions assessing health function in the past 30 days (see eTable 1 
(Appendix)). Each item was scored on a five-point scale ranging from 'none' to 'extreme/cannot do'. For each separate domain, we used factor analysis with polychoric correlations to obtain a factor score which was later converted to scores ranging from 0 to 10 with higher values representing worse health function (Stubbs et al., 2017; Stubbs et al., 2016b).

\subsection{Statistical analysis}

Data from 69 countries were publically available. Of these countries, 18 high-income countries were excluded as the focus of the study was on LMICs, and also because information on psychosis was not collected for the majority of these countries. Of the remaining LMICs, Morocco and Latvia were not included as they lacked information on PA, and Turkey and Slovenia were also excluded due to lack of several variables pertaining to the analysis. Thus, a total of 47 countries, all LMICs according to the World Bank 2003 classification, were included in the analysis (Appendix eTable 2). The current analysis was restricted to those with a self-reported lifetime diagnosis of schizophrenia or psychosis $(\mathrm{n}=$ 2407).

The statistical analysis was performed with Stata 14.1 (Stata Corp LP, College station, Texas). A total of 18 potential correlates of PA were assessed. The selection of these correlates was based on past literature (Suetani et al., 2016; Vancampfort et al., 2012). For all the variables used in the analysis, $<5 \%$ of the data were missing, with the exception of total number of chronic conditions (18.6\%), PA (14.0\%), fruit consumption (11.2\%), wealth (9.4\%), vegetable consumption (8.8\%), and employment status (8.6\%). We conducted multiple imputation of missing values using the mi commands in Stata with chained equations (10 imputations). The variables included in the imputation model were the outcome and all other covariates. In order to assess the correlates of low PA, we conducted random effects logistic regression of a two-level structure in which individuals were level one and country was level two. This analytical method allowed for the adjustment of clustering within country. First, we assessed the significant socio-demographic correlates. For subsequent models, the correlates pertaining to health behavior, and mental and physical health were included individually in the models while adjusting for the significant socio-demographic correlates (sex, age, employment, and setting).

For all regression analyses, the variables were included in the models as categorical variables with the exception of age, sleep/energy, cognition, pain/discomfort, mobility, and number of chronic conditions (continuous variables). We also conducted sensitivity analysis based on complete cases. The results obtained from the imputed and non-imputed datasets were very similar (data not shown). Results from the logistic regression models are presented as odds ratios (ORs) with 95\% confidence intervals (CIs). The level of statistical significance was set at $p<$ 0.05 .

\section{Results}

The final sample included 2407 people with psychosis (41.5\% male) with a mean age of 42.0 years. Sample characteristics are provided in Table 1. The prevalence $(95 \% \mathrm{CI})$ of low PA was $39.2 \%$ (37.0\%-41.2\%). Nearly a third of the sample was in the lowest country-wise wealth quintile, while $52.2 \%$ were unemployed. Depression (32.5\%) and anxiety (28.2\%) were common in the sample.

The socio-demographic correlates of low PA estimated by random effects logistic regression are illustrated in Table 2. Male sex (vs. female $\mathrm{OR}=1.33$ ), age (per one unit increase: $\mathrm{OR}=1.02$ ), unemployment (vs. employed $\mathrm{OR}=2.50$ ), and urban setting (vs. rural OR $=1.75$ ) were significant correlates.

In terms of the other correlates, inadequate fruit consumption was significantly associated with a particularly high odds for low PA (vs. adequate fruit intake $\mathrm{OR}=3.03$ ), while depression (vs. no depression
Table 1

Sample characteristics of individuals with psychosis $(n=2407)$.

\begin{tabular}{|c|c|c|}
\hline Characteristic & Category & [Mean] or $\%(95 \% \mathrm{Cl})$ \\
\hline Physical activity ${ }^{\mathrm{a}}$ & Low & $39.2 \%(37.0 \%-41.2 \%)$ \\
\hline \multicolumn{3}{|l|}{ Socio-demographic factors } \\
\hline Sex & Male & $41.5 \%(39.6 \%-43.5 \%)$ \\
\hline Age (years) & Mean & {$[42.0(41.3-42.6)]$} \\
\hline Marital status & Married/cohabiting & $62.4 \%(60.5 \%-64.3 \%)$ \\
\hline Education & $\geq$ Secondary completed & $27.7 \%(25.9 \%-29.5 \%)$ \\
\hline \multirow[t]{5}{*}{ Wealth } & Poorest & $29.8 \%(27.8 \%-31.7 \%)$ \\
\hline & Poorer & $21.4 \%(19.7 \%-23.2 \%)$ \\
\hline & Middle & $19.2 \%(17.6 \%-20.8 \%)$ \\
\hline & Richer & $16.0 \%(14.4 \%-17.6 \%)$ \\
\hline & Richest & $13.7 \%(12.2 \%-15.1 \%)$ \\
\hline Unemployed & Yes & $52.2 \%(50.1 \%-54.4 \%)$ \\
\hline Setting & Urban & $39.9 \%(37.9 \%-41.9 \%)$ \\
\hline \multicolumn{3}{|l|}{ Health behavior } \\
\hline Current smoking & Yes & $26.4 \%(24.7 \%-28.2 \%)$ \\
\hline Fruit consumption ${ }^{\mathrm{b}}$ & $<5$ servings/day & $93.1 \%(91.9 \%-94.3 \%)$ \\
\hline Vegetable consumption $^{\mathrm{b}}$ & $<5$ servings/day & $95.9 \%(95.0 \%-96.8 \%)$ \\
\hline \multirow[t]{4}{*}{ Alcohol consumption } & Lifetime abstainer & $67.3 \%(65.4 \%-69.1 \%)$ \\
\hline & Non-heavy & $28.5 \%(26.7 \%-30.3 \%)$ \\
\hline & Infrequent heavy & $2.7 \%(2.0 \%-3.3 \%)$ \\
\hline & Frequent heavy & $1.5 \%(1.1 \%-2.0 \%)$ \\
\hline \multicolumn{3}{|l|}{ Mental health } \\
\hline Depression & Yes & $32.5 \%(30.6 \%-34.4 \%)$ \\
\hline Anxiety & Yes & $28.2 \%(26.4 \%-30.0 \%)$ \\
\hline Sleep/energy ${ }^{c}$ & Mean & {$[4.0(3.9-4.1)]$} \\
\hline Cognition ${ }^{\mathrm{c}}$ & Mean & {$[3.8(3.6-3.9)]$} \\
\hline \multicolumn{3}{|l|}{ Physical health } \\
\hline Pain/discomfort ${ }^{\mathrm{C}}$ & Mean & {$[4.3(4.2-4.4)]$} \\
\hline Mobility ${ }^{\mathrm{c}}$ & Mean & {$[3.8(3.6-3.9)]$} \\
\hline Number of chronic conditions ${ }^{\mathrm{d}}$ & Mean & {$[1.02(0.98-1.07)]$} \\
\hline
\end{tabular}

Abbreviation: $\mathrm{CI}$ confidence interval.

a The total amount of moderate to vigorous physical activity over the last week was calculated and those scoring $<150$ min were considered to have low physical activity.

b Mexico is not included as data on fruit and vegetable consumption were not collected.

c These variables had scores ranging from 0 to 10 (higher scores indicating worse conditions).

d Total number of seven chronic conditions assessed.

$\mathrm{OR}=1.33$ ), sleep/energy disturbance, and mobility limitations were also significant correlates (Table 3 ).

\section{Discussion}

To the best of our knowledge, the current study is the largest and first multinational study to investigate PA correlates among people

Table 2

Association between socio-demographic factors and low physical activity in psychosis.

\begin{tabular}{llll}
\hline Characteristic & Category & OR $(95 \% \mathrm{CI})$ & $p$-Value \\
\hline Sex & Female & 1.00 & \\
& Male & $1.33(1.07-1.67)$ & 0.012 \\
Age (years) ${ }^{\mathrm{a}}$ & Per one year increase & $1.02(1.02-1.03)$ & $<0.001$ \\
Marital status & Married/cohabiting & 1.00 & \\
& Other & $1.20(0.98-1.47)$ & 0.076 \\
Education & <econdary & 1.00 & \\
& $\geq$ Secondary completed & $1.30(0.98-1.72)$ & 0.065 \\
Wealth & Poorest & 1.00 & \\
& Poorer & $1.06(0.79-1.43)$ & 0.689 \\
& Middle & $0.85(0.63-1.15)$ & 0.292 \\
& Richer & $1.06(0.75-1.50)$ & 0.733 \\
& Richest & $0.84(0.59-1.19)$ & 0.314 \\
Unemployed & No & 1.00 & \\
& Yes & $2.50(2.02-3.09)$ & $<0.001$ \\
Setting & Rural & 1.00 & \\
& Urban & $1.75(1.38-2.21)$ & $<0.001$
\end{tabular}

Abbreviation: OR odds ratio; $\mathrm{CI}$ confidence interval.

The total amount of moderate to vigorous physical activity over the last week was calculated and those scoring $<150$ min were considered to have low physical activity.

Model is adjusted for all covariates in the Table and the clustering within country.

a Included in the model as a continuous variable. 
Table 3

Association of health behaviors, mental and physical health factors with low physical activity in psychosis.

\begin{tabular}{|c|c|c|c|}
\hline Characteristic & Category & OR $(95 \% \mathrm{CI})$ & $p$-Value \\
\hline \multicolumn{4}{|l|}{ Health behavior } \\
\hline \multirow[t]{2}{*}{ Current smoking } & No & 1.00 & \\
\hline & Yes & $0.90(0.71-1.15)$ & 0.411 \\
\hline Fruit consumption ${ }^{\mathrm{a}}$ & $\geq 5$ & 1.00 & \\
\hline (Servings/day) & $<5$ & $3.03(1.58-5.79)$ & 0.001 \\
\hline Vegetable consumption ${ }^{\mathrm{a}}$ & $\geq 5$ & 1.00 & \\
\hline (Servings/day) & $<5$ & $1.45(0.82-2.58)$ & 0.201 \\
\hline \multirow[t]{4}{*}{ Alcohol consumption } & Lifetime abstainer & 1.00 & \\
\hline & Non-heavy & $0.83(0.65-1.06)$ & 0.129 \\
\hline & Infrequent heavy & $1.16(0.63-2.14)$ & 0.630 \\
\hline & Frequent heavy & $1.17(0.51-2.69)$ & 0.711 \\
\hline
\end{tabular}

$\begin{array}{llll}\text { Mental health } & & & \\ \text { Depression } & \text { No } & 1.00 & \\ & \text { Yes } & 1.33(1.07-1.66) & 0.009 \\ \text { Anxiety } & \text { No } & 1.00 & \\ & \text { Yes } & 1.20(0.96-1.49) & 0.108 \\ \text { Sleep/energy }^{\mathrm{b}} & \text { Per unit increase } & 1.04(1.00-1.07) & 0.048 \\ \text { Cognition }^{\mathrm{b}} & \text { Per unit increase } & 1.03(1.00-1.07) & 0.081 \\ & & & \\ \text { Physical health }_{\text {Pain/discomfort }^{\mathrm{b}}} & \text { Per unit increase } & 1.02(0.98-1.06) & 0.350 \\ \text { Mobility }^{\mathrm{b}} & \text { Per unit increase } & 1.05(1.01-1.09) & 0.009 \\ \text { Number of chronic conditions }^{\mathrm{c}} & \text { Per unit increase } & 0.93(0.84-1.02) & 0.129\end{array}$

Abbreviation: OR odds ratio; $\mathrm{Cl}$ confidence interval.

The total amount of moderate to vigorous physical activity over the last week was calculated and those scoring < 150 min were considered to have low physical activity.

Each variable in the Table was included in separate models adjusting for sex, age, employment status, setting (urban, rural), and clustering within country.

a Mexico is not included as data on fruit and vegetable consumption were not collected.

b These variables had scores ranging from 0 to 10 (higher scores indicating worse

conditions) and were included in the models as continuous variables.

c Total number of seven chronic conditions assessed.

with psychosis, and the first in LMICs. In summary, we found evidence to suggest that across LMICs, socio-demographic factors including male sex, increasing age, being unemployed, and living in an urban environment were associated with low PA. Interestingly, we found that consuming $<5$ servings of fruits a day was associated with low PA, but no relationship was evident for vegetable intake, alcohol or tobacco use. In addition, depression, sleep/energy disturbance, and mobility limitations were associated with low PA. The prevalence of people not meeting PA target levels (39.2\%) was similar to a recent meta-analysis when data were pooled with self-report measures of PA (43.1\%) (Stubbs et al., 2016a).

Our study illustrates that PA is a complex behavior influenced by multiple factors among people with psychosis. Our findings that older age and male sex are associated with low PA have been reported in the general population (Bauman et al., 2012), however, no consistent relationship was observed among these variables in a previous systematic review among people with schizophrenia (Vancampfort et al., 2012), nor in a recent large study in Australia (Suetani et al., 2016). The finding that males are more likely to engage in low levels of PA is concerning, since males with schizophrenia are at increased risk of cardiovascular and metabolic diseases (Vancampfort et al., 2016a; Vancampfort et al., 2015) and associated deaths (Correll et al., 2017; Walker et al., 2015). Thus, facilitating and supporting men with psychosis to engage in PA may be an important strategy for this at-risk group. Our data also indicate that people with psychosis who are unemployed and live in urban environments are more likely to not meet PA targets. Unemployment is common in people with schizophrenia and can lead to social isolation (Marwaha et al., 2007), which will result in less PA and integration with society. The urban-rural PA differential is hypothesized to occur because of differences in safety, transportation, and employment. Previous research has demonstrated that PA behavior of people with psychosis is strongly related to how safe they perceive their neighborhood to be (Vancampfort et al., 2014; Vancampfort et al., 2013). Unsafe traffic situations and higher crime rates in cities prevent people with psychosis from leaving their homes and walking around. Next to this, the availability of motorized transport and the lack of crosswalks, sidewalks and safe bicycle lanes in many cities in LMICs are important barriers for active transportation, and even more so for people with psychosis (Oyeyemi et al., 2016; Vancampfort et al., 2014; Vancampfort et al., 2013). Finally, urban employment (e.g., service-based jobs) usually entails far less physical labor than rural employment (e.g., farming) in LMICs.

Regarding health behavior correlates, we found that a lower daily consumption of fruit but not vegetables was associated with low PA. This is a relationship that has been observed in the general population (Perry et al., 2016) and reinforces the message that health promotion interventions should seek to promote healthy lifestyles among those with schizophrenia, particularly given the poor nutritional intake of this population (Teasdale et al., 2017). The precise reasons why fruit, but not vegetable consumption is associated with PA is not clear and warrants further consideration in future research. The finding that cigarette use was not associated with PA is perhaps surprising and in contrast to an earlier systematic review (Vancampfort et al., 2012). Our results also illustrate that mobility limitations are associated with low PA, a relationship which has been observed in the general population, while low PA itself has been associated with an accelerated risk of developing disability (Tak et al., 2013). We also found that comorbid depression was negatively associated with PA, which is unsurprising given the established relationship between depression and low PA (Schuch et al., 2016a). However, PA is known to improve depressive symptoms in people with major depression (Schuch et al., 2016b) and psychosis (Firth et al., 2015), thus adding to pressing calls to increase PA among those with psychosis.

\subsection{Clinical and policy recommendations}

The current findings suggest a need to tailor PA interventions to different age groups and to consider depression, sleep/energy disturbance, and mobility problems in those with psychosis. We suggest exploring a clinical strategy in which a smaller group of expert physiotherapists and a larger group of clinical practitioners (e.g., nurses) are involved. A stepped-care approach, where people with psychosis start with self-management strategies to adopt and maintain an active lifestyle may be a feasible low-cost strategy in LMIC settings. If patients are not able to achieve the $150 \mathrm{~min}$ recommendations within a certain time frame, they could continue with a manualized approach under the supervision of a non-specialist worker (e.g., nurses). Patients would only be referred to a specialist supervisor (e.g., physiotherapists, exercise physiologists or qualified exercise scientist) if mobility problems prevented the PA target from being achieved or for specific populations such as those with significant somatic co-morbidities or the elderly. Careful consideration of what PA implementation strategies would be most efficacious, and evaluation of this stepped-care approach, is essential (Gorczynski et al., 2017). Second, urban environments in LMICs can concentrate PA barriers for people with psychosis. Therefore, there is a need to explore ways to place promoting PA at the center of urban planning design processes in LMIC cities, and in particular taking into account vulnerable populations such as people with mental illness. There is for example a need for training programs and curricula to increase the awareness of urban planning among public health students, and to develop decision-making support tools and educational materials for urban planning and public health professionals and policy makers (Smit et al., 2011). In addition, employment may serve as an opportunity for people with psychosis to engage in meaningful PA. Thus, interventions seeking to improve employment may serve as an opportunity for people with psychosis to have a valuable role in society and acquire skills for social interaction as well as achieve recommended PA targets. 


\subsection{Limitations}

A number of limitations should be noted. Psychosis was based on a self-reported lifetime diagnosis. Thus, there may be some level of misclassification. However the overall prevalence of psychosis in the countries included in the study was $1.1 \%$, very similar to previously reported prevalence of psychotic disorders in the general population (McGrath et al., 2008). Second, we did not have information on some important correlates that could influence PA such as antipsychotic medication, severity of psychotic symptoms, negative symptoms or social support. Third, PA was measured with a self-report measure and while it is currently the most promising tool in this population currently available, it is subject to recall bias (Soundy et al., 2014). Fourth, it is important to note that engaging in PA that is less than the recommended 150 min per week can have health benefits. For the purposes of this paper, we focused on the international recommended target of $150 \mathrm{~min}$, but we do not wish to diminish the value of PA less than this amount. Finally, the data are cross-sectional and directionality of the relationships observed cannot be deduced with certainty.

\subsection{Conclusion}

In conclusion, our data suggests that across LMICs a number of sociodemographic and health behavior factors influence PA among people with psychosis. The findings provide further evidence for the development of future population-level interventions to increase PA among people with psychosis.

\section{Contributors}

BS, DV and AK conceived the study, conducted analysis and wrote the manuscript. All authors provided critical comments and approved the final version.

\section{Role of funding source}

No direct funding was available for this project.

\section{Conflict of interest}

All authors declare no conflict of interest in relation to this work. FG has received payments for lectures and advisory boards from Lundbeck, Roche, Sunovion, Bristol Myers Squibb and Otsuka and has a family member with professional links to Eli Lilly and GlaxoSmithKline.

\section{Acknowledgments}

Brendon Stubbs and Fiona Gaughran receives funding from the National Institute for Health Research Collaboration for Leadership in Applied Health Research \& Care Funding scheme. The views expressed in this publication are those of the author(s) and not necessarily those of the NHS, the National Institute for Health Research or the Department of Health. Ai Koyanagi's work was supported by the Miguel Servet contract financed by the CP13/00150 and PI15/00862 projects, integrated into the National R + D + I and funded by the ISCIII - General Branch Evaluation and Promotion of Health Research - and the European Regional Development Fund (ERDF-FEDER).

\section{Appendix A. Supplementary data}

Supplementary data to this article can be found online at http://dx. doi.org/10.1016/j.schres.2017.06.025.

\section{References}

Bauman, A.E., Reis, R.S., Sallis, J.F., Wells, J.C., Loos, R.J.F., Martin, B.W., 2012. Correlates of physical activity: why are some people physically active and others not? Lancet 380 (9838), 258-271.

Bishwajit, G., O'Leary, D.P., Ghosh, S., Sanni, Y., Shangfeng, T., Zhanchun, F., 2017. Association between depression and fruit and vegetable consumption among adults in South Asia. BMC Psychiatry 17 (1), 15.

Cifuentes, M., Sembajwe, G., Tak, S., Gore, R., Kriebel, D., Punnett, L., 2008. The association of major depressive episodes with income inequality and the human development index. Soc. Sci. Med. 67 (4), 529-539.

Correll, C.U., Solmi, M., Veronese, N., Bortolato, B., Rosson, S., Santonastaso, P., ThapaChhetri, N., Fornaro, M., Gallicchio, D., Collantoni, E., Pigato, G., Favaro, A., Monaco F., Kohler, C., Vancampfort, D., Ward, P.B., Gaughran, F., Carvalho, A.F., Stubbs, B. 2017. Prevalence, incidence and mortality from cardiovascular disease in patients with pooled and specific severe mental illness: a large-scale meta-analysis of 3,211,768 patients and 113,383,368 controls. World Psychiatry 16 (2), 163-180.

Craig, C., Marshall, A., Sjostrom, M., Bauman, A., Booth, M., Ainsworth, B., Pratt, M., Ekelund, U., Yngve, A., Sallis, J., Oja, P., 2003. International physical activity questionnaire: 12-country reliability and validity. Med. Sci. Sports Exerc. 35 (8), 1381-1395.

Firth, J., Cotter, J., Elliott, R., French, P., Yung, A.R., 2015. A systematic review and metaanalysis of exercise interventions in schizophrenia patients. Psychol. Med. 45 (7), 1343-1361.

Firth, J., Rosenbaum, S., Stubbs, B., Gorczynski, P., Yung, A.R., Vancampfort, D., 2016a. Motivating factors and barriers towards exercise in severe mental illness: a systematic review and meta-analysis. Psychol. Med. 46 (14), 2869-2881.

Firth, J., Stubbs, B., Rosenbaum, S., Vancampfort, D., Malchow, B., Schuch, F., Elliott, R., Nuechterlein, K.H., Yung, A.R., 2016b. Aerobic exercise improves cognitive functioning in people with schizophrenia: a systematic review and meta-analysis. Schizophr. Bull. 43 (3), 546-556.

Freeman, E.E., Roy-Gagnon, M.H., Samson, E., Haddad, S., Aubin, M.J., Vela, C., Zunzunegui, M.V., 2013. The global burden of visual difficulty in low, middle, and high income countries. PLoS One 8 (5), e63315.

Gorczynski, P.F., Sitch, M., Faulkner, G., 2017. Examining methods, messengers and behavioural theories to disseminate physical activity information to individuals with a diagnosis of schizophrenia: a scoping review. J. Ment. Health 1-10.

Hamer, M., Chida, Y., 2009. Physical activity and risk of neurodegenerative disease: a systematic review of prospective evidence. Psychol. Med. 39 (1), 3-11.

Hamer, M., Lavoie, K.L., Bacon, S.L., 2014. Taking up physical activity in later life and healthy ageing: the English longitudinal study of ageing. Br. J. Sports Med. 48 (3), 239-243.

Koyanagi, A., Stickley, A., 2015. The association between sleep problems and psychotic symptoms in the general population: a global perspective. Sleep 38 (12), 1875-1885.

Loerbroks, A., Herr, R.M. Subramanian, S., Bosch, J.A. 2012. The association of asthma and wheezing with major depressive episodes: an analysis of 245727 women and men from 57 countries. Int. J. Epidemiol. 41 (5), 1436-1444.

Mammen, G., Faulkner, G., 2013. Physical activity and the prevention of depression: a systematic review of prospective studies. Am. J. Prev. Med. 45 (5), 649-657.

Marwaha, S., Johnson, S., Bebbington, P., Stafford, M., Angermeyer, M.C., Brugha, T., Azorin, J.M., Kilian, R., Hansen, K., Toumi, M., 2007. Rates and correlates of employment in people with schizophrenia in the UK, France and Germany. Br. J. Psychiatry 191, 30-37.

McGrath, J., Saha, S., Chant, D., Welham, J., 2008. Schizophrenia: a concise overview of incidence, prevalence, and mortality. Epidemiol. Rev. 30, 67-76.

Naci, H., Ioannidis, J.P.A., 2013. Comparative effectiveness of exercise and drug interventions on mortality outcomes: metaepidemiological study. BMJ 347, f5577.

Nelson, M.E., Rejeski, W.J., Blair, S.N., Duncan, P.W., Judge, J.O., King, A.C., Macera, C.A., Castaneda-Sceppa, C., 2007. Physical activity and public health in older adults: recommendation from the American College of Sports Medicine and the American Heart Association. Med. Sci. Sports Exerc. 39 (8), 1435-1445.

Nuevo, R., Chatterji, S., Verdes, E., Naidoo, N., Arango, C., Ayuso-Mateos, J.L., 2012. The continuum of psychotic symptoms in the general population: a cross-national study. Schizophr. Bull. 38 (3), 475-485.

Oyeyemi, A.L., Conway, T.L., Adedoyin, R.A., Akinroye, K.K., Aryeetey, R., Assah, F., Cain, K.L., Gavand, K.A., Kasoma, S.S., Kolbe-Alexander, T.L., Lambert, E.V., Larouche, R., Mos, S.J., Ocansey, R., Onywera, V.O., Prista, A., Tremblay, M.S., Sallis, J.F., 2016. Construct validity of the neighborhood environment walkability scale for Africa. Med. Sci. Sports Exerc. 49 (3), 482-491.

Perry, B., Ciciurkaite, G., Brady, C.F., Garcia, J., 2016. Partner influence in diet and exercise behaviors: testing behavior modeling, social control, and normative body size. PLoS One 11 (12), e0169193.

Rose, G.A., 1962. The diagnosis of ischaemic heart pain and intermittent claudication in field surveys. Bull. World Health Organ. 27, 645-658.

Schuch, F., Vancampfort, D., Firth, J., Rosenbaum, S., Ward, P., Reichert, T., Bagatini, N.C., Bgeginski, R., Stubbs, B., 2016a. Physical activity and sedentary behavior in people with major depressive disorder: a systematic review and meta-analysis. J. Affect. Disord. 210, 139-150.

Schuch, F.B., Vancampfort, D., Richards, J., Rosenbaum, S., Ward, P.B., Stubbs, B., 2016b. Exercise as a treatment for depression: a meta-analysis adjusting for publication bias. J. Psychiatr. Res. 77, 42-51.

Smit, W., Hancock, T., Kumaresen, J., Santos-Burgoa, C., Sanchez-Kobashi Meneses, R., Friel, S., 2011. Toward a research and action agenda on urban planning/design and health equity in cities in low and middle-income countries. J. Urban Health 88 (5), 875-885.

Soundy, A., Roskell, C., Stubbs, B., Vancampfort, D., 2014. Selection, use and psychometric properties of physical activity measures to assess individuals with severe mental illness: a narrative synthesis. Arch. Psychiatr. Nurs. 28 (2), 135-151.

Stubbs, B., Firth, J., Berry, A., Schuch, F.B., Rosenbaum, S., Gaughran, F., Veronesse, N., Williams, J., Craig, T., Yung, A.R., Vancampfort, D., 2016a. How much physical activity do people with schizophrenia engage in? A systematic review, comparative metaanalysis and meta-regression. Schizophr. Res. 176 (2-3), 431-440.

Stubbs, B., Koyanagi, A., Schuch, F.B., Firth, J., Rosenbaum, S., Veronese, N., Solmi, M., Mugisha, J., Vancampfort, D., 2016b. Physical activity and depression: a large crosssectional, population-based study across 36 low- and middle-income countries. Acta Psychiatr. Scand. 134 (6), 546-556.

Stubbs, B., Koyanagi, A., Schuch, F., Firth, J., Rosenbaum, S., Gaughran, F., Mugisha, J., Vancampfort, D., 2017. Physical activity levels and psychosis: a mediation analysis of factors influencing physical activity target achievement among 204186 people across 46 low- and middle-income countries. Schizophr. Bull. 43 (3), 536-545.

Suetani, S., Waterreus, A., Morgan, V., Foley, D.L., Galletly, C., Badcock, J.C., Watts, G., McKinnon, A., Castle, D., Saha, S., Scott, J.G., McGrath, J.J., 2016. Correlates of physical 
activity in people living with psychotic illness. Acta Psychiatr. Scand. 134 (2), 129-137.

Tak, E., Kuiper, R., Chorus, A., Hopman-Rock, M., 2013. Prevention of onset and progression of basic ADL disability by physical activity in community dwelling older adults: a meta-analysis. Ageing Res. Rev. 12 (1), 329-338.

Teasdale, S.B., Ward, P.B., Rosenbaum, S., Samaras, K., Stubbs, B., 2017. Solving a weighty problem: systematic review and meta-analysis of nutrition interventions in severe mental illness. Br. J. Psychiatry 210 (2), 110-118.

Vancampfort, D., 2012. International Organization of Physical Therapy in Mental Health consensus on physical activity within multidisciplinary rehabilitation programmes for minimising cardio-metabolic risk in patients with schizophrenia. Disabil. Rehabil. $34(1), 1-12$.

Vancampfort, D., Knapen, J., Probst, M., Scheewe, T., Remans, S., De Hert, M., 2012. A systematic review of correlates of physical activity in patients with schizophrenia. Acta Psychiatr. Scand. 125 (5), 352-362.

Vancampfort, D., De Hert, M., De Herdt, A., Vanden Bosch, K., Soundy, A., Bernard, P.P., De Wachter, D., Probst, M., 2013. Associations between physical activity and the built environment in patients with schizophrenia: a multi-centre study. Gen. Hosp. Psychiatry 35 (6), 653-658.

Vancampfort, D., De Hert, M., De Herdt, A., Soundy, A., Stubbs, B., Bernard, P., Probst, M., 2014. Associations between perceived neighbourhood environmental attributes and self-reported sitting time in patients with schizophrenia: a pilot study. Psychiatry Res. 215 (1), 33-38.

Vancampfort, D., Stubbs, B., Mitchell, A.J., De Hert, M., Wampers, M., Ward, P.B., Rosenbaum, S., Correll, C.U., 2015. Risk of metabolic syndrome and its components in people with schizophrenia and related psychotic disorders, bipolar disorder and major depressive disorder: a systematic review and meta-analysis. World Psychiatry 14 (3), 339-347.

Vancampfort, D., Correll, C.U., Galling, B., Probst, M., De Hert, M., Ward, P.B., Rosenbaum, S., Gaughran, F., Lally, J., Stubbs, B., 2016a. Diabetes mellitus in people with schizophrenia, bipolar disorder and major depressive disorder: a systematic review and large scale meta-analysis. World Psychiatry 15 (2), 166-174.

Vancampfort, D., Rosenbaum, S., Schuch, F., Ward, P.B., Richards, J., Mugisha, J., Probst, M., Stubbs, B., 2016b. Cardiorespiratory fitness in severe mental illness: a systematic review and meta-analysis. Sports Med. 47 (2), 343-352.

Vancampfort, D., Koyanagi, A., Ward, P.B., Rosenbaum, S., Schuch, F.B., Mugisha, J., Richards, J., Firth, J., Stubbs, B., 2017. Chronic physical conditions, multimorbidity and physical activity across 46 low- and middle-income countries. Int. J. Behav. Nutr. Phys. Act. 14 (1), 6.

Walker, E.R., McGee, R.E., Druss, B.G., 2015. Mortality in mental disorders and global disease burden implications: a systematic review and meta-analysis. JAMA Psychiat. 72 (4), 334-341.

Weinmann, S., Koesters, M., 2016. Mental health service provision in low and middle-income countries: recent developments. Curr. Opin. Psychiatry 29 (4), 270-275.

Wong, K.O., Hunter Rowe, B., Douwes, J., Senthilselvan, A., 2013. Asthma and wheezing are associated with depression and anxiety in adults: an analysis from 54 countries. Pulm. Med. 2013, 929028.

World Health Organization, 2002. International Guide for Monitoring Alcohol Consumption and Related Harm, Geneva.

World Health Organization, 2014. 10 Facts on Physical Activity. 